\begin{tabular}{ll}
\hline Thabiea : Journal of Natural Science Teaching \\
Program Studi Tadris Ilmu Pengetahuan Alam \\
Institut Agama Islam Negeri Kudus \\
http://journal.stainkudus.ac.id/index.php/Thabiea \\
$p-i s s n: 2580-8974, e-i s s n: 2655-898 x$
\end{tabular}

\title{
Pengaruh Media Edmodo Terhadap Hasil Belajar IPA pada Materi Tekanan dengan Model Discovery Learning
}

\author{
Siti Jumaeroh ${ }^{a, 1 *}$, Anggun Zuhaida ${ }^{\text {b,2 }}$ \\ a,bInstitut Agama Islam Negeri Salatiga, Sidorejo, Salatiga, 50716 \\ ${ }^{1}$ sitijumaeroh11@gmail.com ${ }^{*} ;{ }^{2}$ anggunzuh@iainsalatiga.ac.id
}

\begin{tabular}{ll}
\hline & ABSTRAK \\
\hline Kata kunci: & Tujuan dalam penelitian ini adalah untuk mengetahui pengaruh media \\
Edmodo; & Edmodo dengan model pembelajaran Discovery Learning terhadap hasil \\
Discovery Learning; & belajar IPA. Jenis penelitian ini adalah kuantitatif eksperimental semu. \\
Hasil Belajar & Pengambilan sampel dalam penelitian ini dilakukan secara purposive \\
& sampling yaitu kelas VIII-D (kelas eksperimen) dan kelas VIII-E (kelas \\
& kontrol) SMP Negeri 1 Salatiga, masing-masing berjumlah 30 siswa dan \\
& 28 siswa. Hasil penelitian menunjukkan bahwa penggunaan Edmodo \\
& sangat membantu proses pembelajaran siswa, mudah diakses dimana saja \\
& dan kapan saja.Hasil angket menunjukkan bahwa kelas eksperimen lebih \\
& tinggi ketertarikannya terhadap materi pelajaran dibandingkan dengan \\
& kelas kontrol. Hasil uji korelasi terdapat hubungan antara media Edmodo \\
& dengan hasil belajar siswa bernilai 0,453 yang tingkat hubungannya berarti \\
& sedang/cukup. Hasil uji regresi linier sederhana memiliki nilai signifikansi \\
& sebesar 0,015 dengan nilai pengaruh antara dua variabel sebesar 20,5\%. \\
Sehingga dapat disimpulkan bahwa adanya pengaruh media Edmodo \\
dengan model Discovery Learning terhadap hasil belajar IPA materi \\
tekanan pada zat siswa kelas VIII SMP Negeri 1 Salatiga.
\end{tabular}

Key word:

Edmodo;

Discovery Learning;

Learning Outcomes

\begin{abstract}
The Influence of Edmodo Media on Science Learning Outcomes on Pressure Learning Material with the Discovery Learning Model. The purpose of this study was to determine the effect of Edmodo media with Discovery Learning learning models on learning outcomes of Natural Sciences. This type of research is quasi-experimental quantitative. Sampling in this study was conducted by purposive sampling, namely class VIII-D (experimental class) and class VIII-E (control class) SMP Negeri 1 Salatiga, each of which amounted to 30 students and 28 students. The results showed that the use of Edmodo really helped the learning process of students, easily accessed anywhere and anytime. The results of the questionnaire showed that the experimental class had higher interest in the subject matter compared to the control class. Correlation test results there is a relationship between Edmodo media with student learning outcomes worth 0.453 whose level of relationship means moderate / sufficient. Simple linear regression test results have a significance value of 0.015 with a value of influence between the two variables of $20.5 \%$. So it can be concluded that the influence of Edmodo media with the Discovery Learning model on the learning outcomes of science material pressure on the substances of eighth grade students of SMP Negeri 1 Salatiga.
\end{abstract}

Copyright (C) 2019 Institut Agama Islam Negeri Kudus. All Right Reserved global pada dunia pendidikan sangat diperlukan bagi peserta didik untuk memiliki suatu keterampilan khusus dalam bidang Teknologi Informasi dan Komunikasi (TIK). Pada Undang-Undang Nomor 20 Tahun 2003 tentang 
Sistem Pendidikan Nasional pada Pasal 1 Ayat (1) (dalam Sudibjo dan Wasis, 2013: 188) sudah dijelaskan bahwa "Pendidikan adalah usaha sadar dan terencana untuk mewujudkan suasana belajar dan proses pembelajaran agar peserta didik secara aktif mengembangkan potensi dirinya untuk memiliki kekuatan spiritual keagamaan, pengendalian diri, kepribadian, kecerdasan, akhlak mulia, serta keterampilan yang diperlukan dirinya, masyarakat, bangsa, dan negara".

Proses pembelajaran anak kurang didorong untuk mengembangkan kemampuan berfikir dan hanya diarahkan kepada kemampuan untuk menghafal informasi, otak anak dipaksa untuk mengingat dan menimbun berbagai informasi tanpa dituntut untuk memahami informasi yang diingatnya itu untuk dihubungkan dengan kehidupan sehari-hari (Suryanti dan Ferazona, 2016: 68). Padahal dalam kurikulum 2013 proses atau kegiatan pembelajaran ditujukan untuk mengembangkan potensi peserta didik agar memiliki kemampuan hidup sebagai pribadi dan warga negara yang beriman, produktif, kreatif, inovatif, dan afektif, serta mampu berkontribusi pada kehidupan masyarakat (Fikri, Paidi dan Viki, 2018: 1).

Proses pembelajaran terdapat beberapa aspek yaitu metode, pendekatan, model, dan media pembelajaran sebagai alat bantu mengajar. Kedudukan media pembelajaran ada dalam metode pembelajaran. Oleh karena itu fungsi utama dari media pembelajaran adalah sebagai alat bantu mengajar untuk menunjang penggunaan metode pembelajaran yang digunakan oleh guru (Arsyad, 2007: 1).

Media pembelajaran untuk masa sekarang ini tidaklah sedikit khususnya dalam dunia Teknologi Informasi dan Komunikasi (TIK) yang sering disebut dengan e-learning ini membawa pengaruh transformasi pendidikan konvensional ke dalam bentuk digital, baik isi maupun sistemnya. Salah satu bentuk media pembelajaran berbasis e-learning yaitu edmodo. Edmodo (www.edmodo.com) adalah platform microblogging pribadi yang dikembangkan untuk guru dan siswa, dengan mengutamakan privasi siswa. Guru dan siswa dapat berbagi catatan, tautan, dan dokumen (Nurdani, 2016:16-17). Di dalam edmodo ini, bisa berlangsung pembelajaran antara guru dan siswa, bahkan orang tua bisa mengkontrol anaknya saat pembelajaran berlangsung (Sudibjo dan Wasis, 2013: 188).

Selain media pembelajaran, diperlukan juga suatu model pembelajaran. Terdapat berbagai macam model pembelajaran terhadap siswa diantaranya adalah model Discovery Learning. Menurut Hosnan (2014: 282), "Discovery Learning adalah suatu model untuk mengembangkan cara belajar aktif dengan menemukan sendiri, menyelidiki sendiri, maka hasil yang diperoleh akan setia dan tahan lama dalam ingatan. Melalui belajar penemuan, siswa juga bisa belajar berpikir analisis dan mencoba memecahkan sendiri masalah yang dihadapi." Siswa akan memperoleh "kemampuankemampuan yang dimiliki peserta didik setelah ia menerima pengalaman belajarnya" (Sudjana, 2009: 22), apabila didukung dengan media ataupun metode pembelajaran serta suatu model pembelajaran yang sedang berkembang saat ini.

Berdasarkan pemikiran tersebut, dirasa sangat penting untuk peneliti menggunakan media Edmodo dengan model pembelajaran Discovery Learning pada proses pembelajaran IPA materi Tekanan pada Zat terlebih pada era 4.0 ini. Terdapat permasalahan yang dapat dibahas, yaitu: Bagaimana pengaruh media edmodo dengan model pembelajaran discovery learning terhadap hasil belajar IPA materi tekanan pada zat siswa kelas VIII SMP Negeri 1 Salatiga tahun pelajaran 2018/2019?

Tujuan dari penelitian ini adalah untuk mengetahui pengaruh media edmodo dengan model pembelajaran discovery learning terhadap hasil belajar IPA materi tekanan pada zat siswa kelas VIII SMP Negeri 1 Salatiga tahun pelajaran 2018/2019.

\section{Metode}

Penelitian ini menggunakan metode penelitian kuantitatif eksperimental semu, yaitu 
suatu metode yang bersifat validation atau menguji pengaruh satu atau lebih variabel terhadap variabel lain (Sukmadinata, 2008: 5758). Adapun pola desain penelitian ini sebagai berikut:

\begin{tabular}{|llll|}
\hline $\mathbf{R}$ & $\mathbf{Q}_{1}$ & $\mathbf{X}$ & $\mathbf{Q}_{2}$ \\
$\mathbf{R}$ & $\mathbf{Q}_{3}$ & & $\mathbf{Q}_{4}$ \\
\hline
\end{tabular}

Gambar 1 Pola Desain Pretest-Posttest Control Group Design

(Sumber: Sukmadinata, 2008: 58)

Keterangan:

$\mathrm{R}=$ randomisasi Subjek

$\mathrm{Q} 1=$ pretest kelompok eksperimen sebelum diberi treatment

Q3 = pretest pada kelompok kontrol

$\mathrm{X}=$ treatment yang diberikan ( variabel independen)

$\mathrm{Q} 2=$ posttest akhir pada kelompok yang diberi treatment

Q4= posttest pada kelompok kontrol.

Lokasi penelitian ini dilaksanakan di SMP Negeri 1 Salatiga. Penelitian dilaksanakan pada waktu semester dua tahun pelajaran 2018/2019 yaitu pada tanggal 28 Januari - 09 Februari 2019. Pengambilan sampel dilakukan dengan teknik Purposive sampling. Purposive sampling adalah teknik penentuan sampel dengan pertimbangan tertentu (Sugiyono, 2016: 81-85). Peneliti menggunakan kelas VIII-D sebagai kelas eksperimen dan kelas VIII-E sebagai kelas kontrol dengan alasan kedua kelas tersebut mendapat peringkat yang seimbang. Instrumen yang digunakan dalam penelitian ini adalah tes dan nontes (angket).

Pada uji regresi linier, jika nilai signifikansi (Sig.) kurang dari probabilitas 0,05 mengandung arti bahwa ada pengaruh antara dua variabel dan sebaliknya jika nilai signifikansi lebih besar dari probabilitas 0,05 mengandung arti tidak ada pengaruh antara dua variabel (Sugiyono, 2010: 270).

\section{Hasil dan pembahasan}

Edmodo (www.edmodo.com) adalah platform microblogging pribadi yang dikembangkan untuk guru dan siswa, dengan mengutamakan privasi siswa (Nurdani, 2016:16-17). Edmodo dilengkapi dengan berbagai fitur, yaitu (Basori, 2013:99-105) : assignment, file and links, quiz, polling, gradebook, library, award badges, parents code.

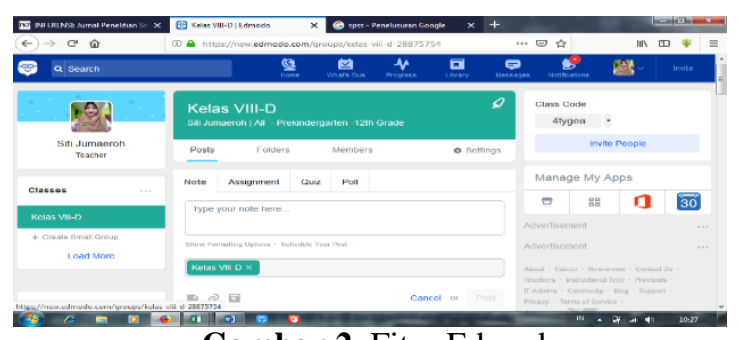

Gambar 2. Fitur Edmodo

(Sumber: Schreenshot Peneliti)

Selain menggunakan media Edmodo, peneliti mengkolaborasikan dengan model pembelajaran Discovery Learning. Cintia, Kristin, \& Anugraheni (2018:71) mengemukakan bahwa model Discovery Learning memiliki ciri tersendiri yaitu pembelajaran berpusat pada siswa. Edmodo dengan model pembelajaran Discovery Learning digunakan untuk membantu dalam proses pembelajaran IPA materi Tekanan pada Zat.

Berdasarkan hasil uji korelasi dengan menggunakan SPSS 21.0 bivariate pearson pada Tabel 1 terdapat hubungan antara media Edmodo dengan hasil belajar siswa bernilai 0,453 yang tingkat hubungannya berarti sedang/cukup. Karena bagi mereka Edmodo adalah suatu hal yang baru sehingga membuat mereka semakin semangat belajar. 
Tabel 1. Hasil Uji Korelasi dengan SPSS 21.0

\begin{tabular}{ccccc}
\hline & & \multicolumn{3}{c}{ Correlations } \\
\cline { 3 - 5 } & & Zero-order & Partial & Part \\
\hline \multirow{4}{*}{1} & (Constant) & & & \\
& $\begin{array}{c}\text { Posttest } \\
\text { Eksperimen }\end{array}$ & .453 & .453 & .453 \\
\hline
\end{tabular}

Sedangkan adanya pengaruh atau tidak pada penelitian ini diuji dengan menggunakan uji regresi linier sederhana SPSS 21.0 dengan hasil sebagai berikut:

Tabel 2. Uji Regresi Linier Sederhana

\begin{tabular}{|c|c|c|c|c|c|}
\hline & \multicolumn{2}{|c|}{$\begin{array}{c}\text { Unstandardized } \\
\text { Coefficients }\end{array}$} & \multirow{2}{*}{$\begin{array}{c}\text { Standardize } \\
\mathrm{d} \\
\text { Coefficients } \\
\text { Beta }\end{array}$} & \multirow[t]{2}{*}{$\mathrm{t}$} & \multirow[t]{2}{*}{ Sig. } \\
\hline & B & $\begin{array}{l}\text { Std. } \\
\text { Error }\end{array}$ & & & \\
\hline (Constant) & 38.387 & 12.417 & & 3.091 & .005 \\
\hline $\begin{array}{l}\text { Posttest } \\
\text { Eksperimen }\end{array}$ & .417 & .161 & .453 & 2.593 & .015 \\
\hline
\end{tabular}

Dari Tabel 2 dapat diketahui bahwa nilai signifikansi (Sig.) sebesar 0,015 lebih kecil dari probabilitas 0,05 , sehingga dapat disimpulkan bahwa terdapat pengaruh antara media Edmodo dengan model pembelajaran Discovery Learning terhadap hasil belajar IPA. Dari Tabel 1 juga diketahui niali a sebesar 38,387 dan nilai b sebesar 0,417 yang artinya setiap penambahan 1\% media Edmodo , hasil belajar IPA akan meningakat 0,417. Maka persamaan regresi sebesar: $\mathrm{Y}=38,387+0,417 \mathrm{X}$.

Pada Tabel 3 diketahui bahwa nilai $R$ Square adalah 0,205, maka jika dimasukkan pada rumus:

$K P=r^{2} \times 100 \%$

$K P=0,205 \quad x 100 \%$

$K P=20,5 \%$

Besarnya pengaruh media Edmodo pada model pembelajaran Discovery Learning dengan hasil belajar IPA sebesar 20,5\% atau bisa dikatakan cukup mempengaruhi. Sedangkan $79,5 \%$ belum terpenuhi dikarenakan kurangnya penguasaan materi maupun media oleh peneliti.

Tabel 3. Hasil Uji $R$ Square dengan SPSS 21.0

\begin{tabular}{ccccc}
\hline Model & $\mathrm{R}$ & $\begin{array}{c}\mathrm{R} \\
\text { Square }\end{array}$ & $\begin{array}{c}\text { Adjuste } \\
\mathrm{d} \mathrm{R} \\
\text { Square }\end{array}$ & $\begin{array}{c}\text { Std. Error of the } \\
\text { Estimate }\end{array}$ \\
\hline 1 & $.453^{\mathrm{a}}$ & .205 & .175 & 7.085 \\
\hline
\end{tabular}

Berikut hasil angket pada kelas eksperimen dan kontrol:

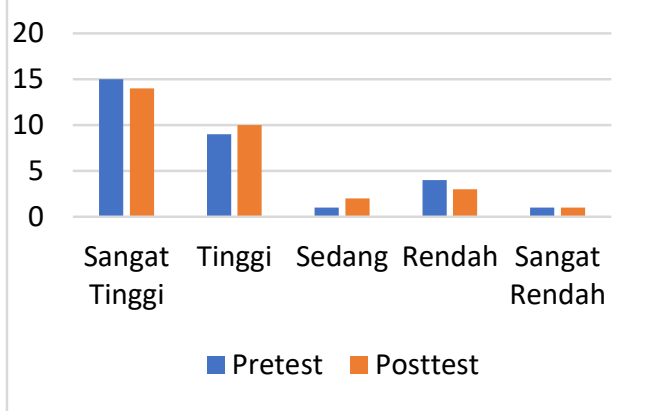

Gambar 4. Angket Kelas Eksperimen

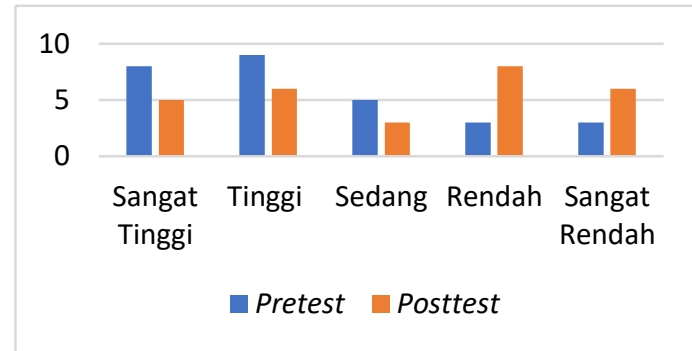

Gambar 5. Angket Kelas Kontrol

Dari hasil Gambar 4 bahwa angket kelas eksperimen pada saat post-angket lebih tinggi dibandingkan dengan pre-angket. Dikarenakan pada saat pre-angket siswa belum mengetahui media Edmodo.

Gambar 5 angket kelas kontrol menunjukkan bahwa kelas kontrol hasil postangket lebih dominan rendah. Karena mereka tidak menggunakan media edmodo dan belum mengetahui sama sekali tentang edmodo. 


\section{Simpulan}

Berdasarkan penelitian yang telah dilakukan, dapat disimpulkan bahwa terdapat hubungan antara media Edmodo dengan hasil belajar siswa bernilai 0,453 pada SPSS 21.0 bivariate pearson yang tingkat hubungannya berarti sedang/cukup. Karena bagi mereka Edmodo adalah suatu hal yang baru sehingga membuat mereka semakin semangat belajar. Pengaruh penggunaan pembelajaran Discovery Learning dengan hasil belajar IPA materi Tekanan pada Zat Siswa Kelas VIII SMP Negeri 1 Salatiga. Dapat dilihat pada uji hipotesis menggunakan regresi linier sederhana dengan nilai signifikansi sebesar 0,015 dan $\mathrm{R}$ Square sebesar 0,205 menunjukkan bahwa terdapat pengaruh antara media Edmodo pada model Discovery Learning dengan hasil belajar IPA. Hasil uji angket juga menunjukkan bahwa kelas eksperimen lebih mudah menangkap materi pelajaran dengan menggunakan Edmodo jika dibandingkan dengan kelas kontrol yang masih melakukan pembelajaran secara konvensional.

\section{Referensi}

Abdullah, Mikrajuddin. 2016. Fisika Dasar I $B$. Bandung: ITB Press.

Arsyad, Azhar. 2007. Media Pembelajaran. Jakarta: PT. Rajagrafindo Persada.

Basori. 2013. Pemanfaatan Social Learning Nerwork "Edmodo" Dalam Membantu Perkuliahan Teori Bodi Otomotif Di Prodi Ptm Jptk FKIP UNS. Jurnal JIPTK, 6 (2): 99-105.

Cintia, Nichen Irma, dkk. 2018. Penerapan Model Pembelajaran Discovery Learning Untuk Meningkatkan Kemampuan Berpikir Kreatif Dan Hsil Belajar Siswa. Jurnal Perspektif Ilmu Pendidikan, 32 (1): 71.

Fikri., A.A., Ismah, V., \& Paidi, P. (2019). Pengembangan perangkat pembelajaran model Guided Inquiry untuk meningkatkan creative thinking Siswa.
Thabiea: Journal of Natural Science Teaching. Vol (1)(01): 1-8.

Hosnan. 2016. Pendekatan Saintifik dan Kontekstual dalam Pembelajaran Abad 21. Bogor: Ghalia Indonesia.

Nurdani, Alif Rahardhika. 2016. Penggunaan Media Edmodo Untuk Meningkatkan Hasil Belajar Siswa Pada Mata Pelajaran Dasar-Dasar Perhitungan Survei Pemetaan Kelas X Geomatika SMK N 3 Salatiga dan SMK N 1 Kedungwuni Pekalongan. Skripsi tidak diterbitkan. Semarang: Fakultas Teknik Uneversitas Negeri Semarang.

Sudibjo, Ari, Wasis. 2013. Penggunaan Media Pembelajaran Fisika dengan E-Learning Berbasis Edmodo Blog Education pada Materi Alat Optik untuk Meningkatkan Respons Motivasi dan Hasil Belajar Siswa di SMP Negeri 4 Surabaya. Jurnal Inovasi Pendidikan Fisika, 2 (3): 188.

Sudjana, Nana. 2009. Penilaian Hasil Proses Belajar Mengajar. Bandung: PT. Remaja Rosdakarya.

Sugiyono. 2010. Metode Penelitian Pendidikan Pendekatan Kuantitatif, Kualitatif, dan $R \& D$. Bandung: Alfabeta.

2016. Metode Penelitian Kuantitatif, Kualitatif, dan $R \& D . \quad$ Bandung: Alfabeta.

Sukmadinata, Nana Syaodih. 2008. Metode Penelitian Pendidikan. Bandung: PT. Remaja Rosdakarya.

Suryanti, Sepira Ferazona. 2016. E-learning Sebagai Media Pembelajaran Interaktif Berbasis Teknologi Informasi. Jurnal Ilmiah Foristek, 2 (1): 68. 